https://doi.org/10.21670/ref.1811011

Artículos

\title{
Mercados de trabajo en regiones fronterizas y no fronterizas de México, 2000-2010
}

\section{Border and no-border labor markets in Mexico, 2000-2010}

Recibido el 12 de junio de 2017. Aceptado el 23 de marzo de 2018. Publicado el 13 de junio de 2018.

${ }^{*}$ Autor para correspondencia: Marlene Solís, correo electrónico: msolis@colef.mx

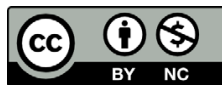

Esta obra está protegida bajo una Licencia Creative Commons Atribución-NoComercial 4.0 Internacional.

\author{
${ }^{\text {a }}$ El Colegio de la Frontera Norte, Departamento de Estudios Sociales, México, correo electrónico: \\ msolis@colef.mx \\ ${ }^{\mathrm{b}}$ Universidad de Granada, Facultad de Ciencias Políticas y Sociología, España, correo electrónico: \\ atrinida@ugr.es \\ ${ }^{c}$ Universidad de Granada, Departamento de Sociología, España, correo electrónico: \\ rsoriano@ugr.es
}

\section{Resumen}

El objetivo del artículo es describir la interrelación entre los mercados de trabajo, la estructura productiva y los modelos de desarrollo regional. Partiendo de las teorías de la sociología del trabajo y el desarrollo, planteamos una metodología macro-estructural, de corte descriptivo, basado en la comparación del comportamiento de mercados de trabajo locales, durante el periodo 2000-2010. Los casos de estudio fueron los estados de Baja California y Puebla, representativos de dos modelos de desarrollo regional: fronterizo y no fronterizo. Como principal resultado se identificó que en ambos contextos se presenta un proceso de precarización del mercado de trabajo, pero que responde a dinámicas particulares y afecta a poblaciones diferentes. Si bien, en este trabajo se logra conocer con mayor profundidad los efectos de la crisis económica y la relocalización industrial en el territorio, el estudio se podría ampliar para mostrar las limitaciones de otros modelos de desarrollo.

Palabras clave: mercado de trabajo, relocalización industrial, estructura productiva, desarrollo regional.

\section{Abstract}

The article aims to describe the interrelation of labor markets, the productive structure and regional development models. Based on the theories of Sociology of work and development, we propose a macro-structural methodology, cutting descriptive, based on the comparison of the behavior of local labor markets, during the period 2000-2010. The case studies were the States of Baja

CÓMO CITAR: Solís, M., Requena, A. T. y Soriano, R. M. (2018). Mercados de trabajo en regiones fronterizas y no fronterizas en México, 2000-2010 [Border and no-border labor markets in Mexico, 2000-2010]. Estudios Fronterizos, 19, e011. doi:https://doi. org/10.21670/ref.1811011 
California and Puebla, representative of two models of regional development: a border and non-border one. As main result, it was identified in both contexts a process of precariousness of the labor market, but responded to particular dynamics and affecting different populations. Although, in this work is accomplished to meet more fully the effects of the economic crisis and industrial relocation in the territory, the study could be expanded to show the limitations of other models of development.

Keywords: labor market, industrial relocation, productive structure, regional development.

\section{Introducción}

El objetivo general del artículo es mostrar la interrelación entre la estructura productiva, el mercado de trabajo y los modelos de desarrollo regional en México. A partir de este interés, proponemos la comparación de una región fronteriza y otra no fronteriza, considerando que se presentan diferentes formas de inserción en los procesos de globalización. La primera de estas regiones es representada por el estado de Baja California en el norte y la segunda por el estado de Puebla en el centro del país. Con este recurso metodológico se dará cuenta del papel del territorio en la configuración de los mercados de trabajo, en su dinámica y sus características.

El desarrollo económico y social del país presenta enormes diferencias regionales producto de distintos procesos históricos y debido a la centralidad que tuvo la zona metropolitana de la Ciudad de México en la industrialización del país durante principios y mediados del siglo xx. Asimismo, podemos constatar los impactos diferenciados en el territorio por el cambio de un modelo de desarrollo basado en la sustitución de importaciones a otro de apertura hacia el exterior, en el que la globalización económica ha jugado un papel de primer orden, generando procesos adicionales ligados a la relocalización de empresas en el mundo. En este nuevo y persistente modelo de desarrollo económico, la frontera norte ha sido punta de lanza en la apertura hacia el exterior y la integración con Estados Unidos y Canadá, mediante la firma del Tratado de Libre Comercio de América del Norte (TLCAN), y la importancia de la actividad productiva de las llamadas maquiladoras.

En la última década, esta región fronteriza ha transitado por fuertes cambios asociados con las crisis económicas de 2001 y de 2008 y a procesos inherentes a la industria maquiladora, la cual entró en un periodo de estancamiento, generando tasas de desempleo inéditas en estos contextos. Con ello, ocurren también cambios en la estructura ocupacional, incrementándose la importancia de las actividades informales y por cuenta propia. La industria maquiladora, en esta última década, dejó de ser un factor de atracción para la población migrante, por lo que se presentó una disminución en el componente social del crecimiento demográfico, al menos en ciudades como Ciudad Juárez y Tijuana.

Por otra parte, desde principios de los años ochenta, las empresas maquiladoras, sobre todo del sector textil, se trasladaron a otras regiones no fronterizas. En particular, en el estado de Puebla se inicia un proceso intensivo de producción de prendas de ropa para la exportación, además de que la industria automotriz — de más larga data en la región- se reestructura para privilegiar la producción para el mercado 
internacional. En esta región, también se han presentado tendencias recesivas que han venido a disminuir drásticamente la presencia de empresas de confección en el Valle de Tehuacán, mientras que la flexibilización del trabajo en otros sectores ha impactado negativamente los niveles de empleo en los últimos años, impulsando con ello la emigración, ya sea al interior del país o hacia los Estados Unidos.

A lo largo del artículo destacamos los impactos de la relocalización industrial en ambas regiones y de la crisis económica del presente siglo en los mercados de trabajo, a través del análisis de los cambios en la estructura productiva, el mercado local de trabajo y la estructura ocupacional. Una de las características que ha estado definiendo a los mercados de trabajo en México durante los último años, es la disminución de la calidad de los empleos, de manera que creemos necesario introducir el análisis de la heterogeneidad y la precarización laboral como principales rasgos estructurales de los mercados de trabajo en México para entender las diferencias regionales (Mora, 2005; Pacheco, 2004; Rojas y Salas, 2011).

La heterogeneidad laboral se encuentra relacionada con la estructura productiva y la diversidad de formas de subsunción de la fuerza de trabajo en el capitalismo y ha sido una característica propia de las economías llamadas emergentes, como la mexicana; mientras que la precarización del trabajo asalariado se encuentra relacionada con los cambios en las economías por la reestructuración productiva y la difusión de la flexibilidad productiva que han generado un deterioro en la calidad de los empleos.

El estudio que se presenta es de carácter macroestructural y comprende el periodo 2000-2010. Los indicadores que se sistematizan para describir los perfiles de los mercados locales de trabajo y las estructuras productivas, se construyen con fuentes de información secundaria, como son los censos de población y vivienda de 2000 y 2010, la Encuesta nacional de ocupación y empleo (Enoe) de 2010 y otras fuentes estadísticas generadas por el Instituto Nacional de Estadística y Geografía (Inegi), el Consejo Nacional para la Evaluación de la Política Social (Coneval), así como el Consejo Nacional de Población (Conapo).

Hemos estructurado el texto en tres secciones: en la primera se exponen los elementos teóricos que guían esta investigación, fundados en la economía política y la sociología del trabajo; la segunda se dedica a describir los cambios en la actividad productiva en Baja California y Puebla, y los procesos de poblamiento que han caracterizado a estos territorios en las últimas décadas; en la tercera sección se presenta un análisis de la dinámica y composición de los mercados de trabajo, de su estructura, y de la segregación ocupacional por sexo y condición migratoria; para finalizar, en las conclusiones se identifican las diferencias en la estructura productiva y ocupacional de las dos regiones, su relación con la precariedad laboral, así como las distintas afectaciones tanto para los hombres como para las mujeres, y para la población migrante, argumentando que la heterogeneidad laboral de ambas regiones responde a procesos de industrialización de momentos históricos distintos, con permanencias de formas ocupacionales tradicionales precarias y, al surgimiento de un tipo distinto de empleos precarios, sobre todo, en la región fronteriza. 


\section{Elementos teóricos para el análisis del mercado de trabajo}

Esta investigación tiene como referentes disciplinarios a la economía política, la demografía y la sociología del trabajo, ${ }^{1}$ en particular, recupera los planteamientos de la escuela latinoamericana sobre el desarrollo. Estas teorías han explicado las características estructurales de los países en desarrollo, considerando su posición geopolítica, es decir, que el sistema capitalista se ha presentado en un contexto de colonización y posterior independencia.

Por su parte, la sociología del trabajo ha avanzado en el conocimiento de las especificidades de los mercados de trabajo en estas economías, proponiendo conceptos como informalidad, trabajosatípicos, precariedad laboral ysegregación ocupacional. Ambos enfoques disciplinarios aportan elementos fundamentales para entender la interrelación entre la estructura productiva, el mercado de trabajo y el modelo de desarrollo.

De acuerdo con uno de los estudiosos del desarrollo (Prebisch, 1963), la principal característica de las economías de los países no desarrollados ha sido la heterogeneidad estructural, es decir, la existencia de ramas o actividades cuya productividad media es muy similar a la de los grandes centros industriales, al mismo tiempo que otro conjunto de actividades tiene una productividad baja, que implica formas de subempleo. Otros autores, como Furtado (1967), han sostenido que la heterogeneidad estructural y la persistencia de formas de producción atrasadas son un rasgo específico del llamado subdesarrollo, ${ }^{2}$ que tiende a reproducirse y perpetuarse; en contraste, en las economías desarrolladas se observaba una tendencia hacia la homogenización de la estructura productiva y la creciente salarización de la fuerza de trabajo, aunque esta tendencia se ha venido cuestionando en las últimas décadas, desde la crisis del estado del bienestar y el vuelco hacia el neoliberalismo, que han extendido el riesgo y la precarización laboral a todo el mundo, como señala Beck (2006).

Para Di Filippo y Jadue (1976), la heterogeneidad estructural se refiere a la coexistencia de formas productivas, relaciones sociales y modos de dominación propias de distintas fases y modalidades de desarrollo; en particular, esta heterogeneidad de la estructura productiva explicaba la permanencia del trabajo no asalariado, aún en la época del modelo de desarrollo por sustitución de importaciones. ${ }^{3}$

Más recientemente, al analizar los efectos de la globalización en el empleo en México, Guillén (2005) señala que la heterogeneidad estructural se ha ampliado y ha complejizado las relaciones entre el sector moderno y el atrasado. Este autor señala también que el modelo de desarrollo basado en la apertura hacia el exterior ha permitido la inserción de las economías — de países como México—en la globalización desde una posición periférica, participando de las cadenas globales de producción

\footnotetext{
${ }^{1}$ Este estudio con raíces en la sociodemografía, tiene el propósito de reconstruir y analizar el mercado de trabajo, la estructura productiva y los modelos de desarrollo regional, por tanto, se encuentra fuera de nuestro interés demostrar relaciones causales entre estas dimensiones. El punto de partida, o hipótesis de trabajo, es que las diferencias regionales se expresan en perfiles específicos de mercados de trabajo.

${ }^{2}$ Si bien se trata de un proceso que ocurre con especial intensidad en los países menos desarrollados, la dinámica del capitalismo en todo el mundo se basa en la gestación de modos de captura y subsunción del trabajo cada vez más heterogéneos (Mezzadra, 2012).

${ }^{3}$ De acuerdo con Mallorquín (2017) y Osorio (2003) el concepto de heterogeneidad estructural y la idea de su persistencia en las matrices productivas de países subdesarrollados, por las condiciones históricas en las que se desenvuelve el capitalismo en estos países, se mantiene vigente en el pensamiento neoestructuralista latinoamericano de las últimas décadas.
} 
en procesos que demandan fuerza de trabajo barata. Por su parte, Mora (2010) encuentra que en este nuevo modelo de desarrollo, la heterogeneidad productiva se ha profundizado de tal manera que se reproduce la diferenciación social en el trabajo y la precariedad laboral alcanza a nuevos sectores de trabajadores.

El debate sobre precariedad laboral inicia en Europa a inicios de los años setenta, mientras que en México esta noción adquiere importancia en las últimas décadas. Esta aparente falta de interés sobre el tema, se debió precisamente a la persistencia de la heterogeneidad estructural y laboral en el país y a la asociación del trabajo no asalariado con las nociones antes mencionadas, es decir, con el subempleo, la marginalidad y la informalidad (Pacheco, 2004).

Lo problemático de las nociones de trabajo atípico y trabajo precario, residen en que no todo el trabajo atípico es precario, ni todo trabajo precario es atípico, aunque ambos conceptos se refieren a trabajos que se alejan de un estándar. La distinción entre ambos reside en que la precariedad alude a un estándar de calidad, mientras que en el trabajo atípico el referente es un tipo de trabajo que se relacionaba con formas de subsunción de la fuerza de trabajo ligadas a la etapa de producción taylorista y a una modernidad que prometía un progreso a través de la integración social por el trabajo asalariado, es decir, cuando la flexibilidad laboral y la economía de servicios aún se encontraban en ciernes.

Desde nuestro punto de vista, conviene recuperar la noción de trabajo atípico para referirse a aquel "no subordinado a un solo patrón, o integrado a una sola empresa, sin contrato por tiempo indeterminado, sin tiempo completo, desprotegido, riesgoso pero no necesariamente precario; también aquellos en los que el cliente está implicado directamente en la producción" (De la Garza, 2011, p. 64). La importancia, la dinámica y la naturaleza del trabajo atípico se puede diferenciar según la rama económica de la que se trate y del territorio donde se desenvuelva un determinado modelo de desarrollo, de tal manera que puede asociarse con procesos de proletarización y a economías de subsistencia, sobre todo, en las localidades rurales; o a procesos de terciarización del proceso productivo o terciarización de la economía (por el mayor peso del sector servicios).

Mientras que para referirnos a la calidad del empleo, nos parece fundamental tomar como referente la propuesta de trabajo decente de la Organización Internacional del Trabajo (огт), que implica considerar al trabajo como un derecho social, y por tanto, como parte de la ciudadanía:

El trabajo decente sintetiza las aspiraciones de las personas durante su vida laboral. Significa la oportunidad de acceder a un empleo productivo que genere un ingreso justo, la seguridad en el lugar de trabajo y la protección social para las familias, mejores perspectivas de desarrollo personal e integración social, libertad para que los individuos expresen sus opiniones, se organicen y participen en las decisiones que afectan sus vidas, y la igualdad de oportunidades y trato para todos, mujeres y hombres (oIT, 2017, párr. 1).

En esta investigación, hacemos un análisis de los indicadores oficiales de la calidad de los empleos, a fin de mostrar las diferencias por región y el papel del territorio en la configuración de los distintos procesos de precarización laboral, entendida como la pérdida de las cualidades del trabajo decente y que van dirigidos tanto a la proletarización de la fuerza de trabajo, como a su abaratamiento y a la flexibilización de la relación laboral. 
Por otro lado, las evidencias sobre la segregación ocupacional han permitido mostrar la importancia de la discriminación para explicar la preponderancia de ciertas poblaciones en empleos de menor calidad. En primer lugar, aludiendo a la desigualdad existente entre los empleos femeninos y masculinos, siendo las mujeres quienes se ocupan en empleos de menor calidad, pero también —y sobre todo en los mercados de trabajo en la frontera norte de México— se ha mostrado que la condición migratoria, es decir, el ser o no inmigrante, implica diferencias respecto a la población nativa, que devienen en segregación ocupacional (Acosta, Reyes y Solís, 2015; García, 1989). ${ }^{4}$

Una desigual estructura de oportunidades ocupacionales por sexo, por condición migratoria o por origen étnico, o cualquier otro sistema de diferenciación social genera segregación vertical, cuando se ocupan puestos de menor nivel jerárquico; y horizontal, cuando se configuran ocupaciones "propias" para cada grupo (femeninos, masculinos) (García, 1989). En lo que resta del trabajo daremos cuenta de la segregación horizontal.

\section{Los contextos regionales: Economía y fuerza de trabajo}

Esta sección se encuentra compuesta por dos apartados: Globalización y modelos de desarrollo, en la que se profundiza sobre las diferencias regionales; y El proceso de poblamiento, en el que se muestra cómo se expresan estas diferencias en las dinámicas de crecimiento de la población en ambos estados de la república.

\section{Globalización y modelos de desarrollo regional}

La comparación de los mercados de trabajo de Puebla y Baja California, ${ }^{5}$ cobra sentido si pensamos que ambos territorios han sido afectados por el proceso de globalización que está en marcha desde hace varias décadas, pero con expresiones distintas. Si tomamos como hilo conductor el proceso de industrialización que se presenta en México con la relocalización de empresas extranjeras y la apertura comercial de la economía del país, es posible situar a cada una de las dos regiones en distintos puntos de la trayectoria que ha seguido este proceso. Baja California, siendo un estado fronterizo, forma parte de lo que María Eugenia De la O (2006) llamó la frontera histórica de la maquiladora, debido a que fue en los estados colindantes con Estados Unidos donde inició, a mediados de los sesenta, la instalación de las primeras empresas maquiladoras, mientras que el estado de Puebla, forma parte del tercer eje emergente de la maquiladora, que se presenta durante la década de los noventa, cuando se

\footnotetext{
${ }^{4}$ La población indígena es también vulnerable y ocupa los empleos más precarios en Puebla, principalmente, pero también en Baja California. Aunque en este contexto, esta población tiene la doble condición de ser indígenas y migrantes, sobre todo en el Valle de San Quintín (Velasco, Coubés y Zlolniski, 2015).

${ }^{5} \mathrm{Si}$ bien los estados de la república mexicana seleccionados no son en sí mismos regiones, pueden considerarse representativos de regiones fronterizas y no fronterizas. Es un criterio de funcionalidad, ya que al ser territorios definidos en términos administrativos, podemos acceder a las estadísticas que se generan por el gobierno.
} 
instalan cientos de fábricas para la exportación de origen mexicano, estadounidense y coreano, en la Sierra Mixteca, la Sierra Norte y el Valle de Tehuacán. La industria del textil y de confección de ropa fue la rama productiva que llegó a ciudades y zonas rurales del estado de Puebla. En Tehuacán, se instalaron principalmente fábricas de pantalones de mezclilla para la exportación, con marcas como Navarra, Tommy Hilfiger, Polo, Ralph Laurent, Dockers, Guess y otros (De la O, 2006). Por otra parte, la industria automotriz, que es de vieja data en el estado de Puebla, por la presencia de la Volkswagen instalada allí desde 1964, ha pasado desde los años noventa por un proceso de reestructuración productiva para responder a las exigencias de la apertura económica y la competencia en el mercado mundial. En los años recientes, la industria automotriz se ha fortalecido en esta región por la llegada de nuevas ensambladoras, tal es el caso de la empresa Audi.

El estado de Baja California como parte de la región histórica de la maquiladora, ha sido una de las zonas geográficas de mayor dinamismo por la industria maquiladora, cuya característica principal ha sido la heterogeneidad (en cuanto sector de actividad, tamaño de las empresas y organización de la producción). Aunque las empresas que predominan en dicha entidad son de origen estadounidense, a partir de los años noventa, las de origen asiático (tales como Sony, Sanyo y Sharp) ganaron una presencia considerable. Al mismo tiempo, se presentó cierta especialización productiva, al predominar las empresas de ensamble de televisores.

La comparación de los mercados de trabajo de estas entidades cobra sentido, entonces, mostrando los distintos momentos en que sus economías han sido impactadas por la relocalización industrial de empresas extranjeras en México, siendo uno de los procesos económicos más importantes de la globalización. Ahora bien, esta industrialización se conjuga con los modelos de desarrollo regional, que diferencian la región noroeste de México de la región centro, a la que pertenece el estado de Puebla.

En Baja California, la actividad productiva se concentraba, a mediados del siglo pasado, en la producción agroindustrial en el Valle de Mexicali, destacándose la producción del algodón, mientras que en Tijuana, la ciudad con mayor número de habitantes del estado, tenía una vocación comercial y turística. La economía local de los centros urbanos de Baja California se ha encontrado, desde entonces, fuertemente ligado a la dinámica fronteriza del flujo de personas y mercancías, por lo que se ha constituido históricamente en una región transfronteriza, en la que los empleos en el condado de San Diego, inclusive hasta la ciudad de Los Ángeles, son parte de las opciones de empleo para miles de personas que cruzan diariamente las garitas para asistir a sus trabajos. Por otra parte, durante los años noventa, se empieza a desarrollar el Valle de San Quintín, al sur del estado, como una zona de actividad de la agroindustria para la exportación.

Mientras que el estado de Puebla, siendo parte del centro del país, se encuentra ligado a las dinámicas de la industrialización del periodo de sustitución de importaciones, y fue la industria textil una de las más importantes que se desarrollaron en este territorio. Además de que la actividad agrícola ha jugado un papel muy importante, ya que una proporción significativa de la población habita en localidades rurales y se encuentra compuesta principalmente por comunidades indígenas: mixtecos, nahuas, mazatecos, popoloca, totonacas y otomíes. Asimismo, la industria automotriz, con la planta de volkswagen, ha representado un polo de crecimiento muy importante, sobre todo para la ciudad capital del estado. 
En cuanto a la participación en la actividad económica nacional, ambas entidades han tenido durante la última década una participación similar en el producto interno bruto (Рів) nacional de alrededor de $3 \%$. En los últimos cinco años, Puebla incrementó ligeramente su participación y Baja California tuvo una tendencia a la baja, de tal manera que el ritmo de crecimiento del PIB, para ambas entidades en 2014, fue menor al promedio observado a nivel nacional (Inegi, s.f.).

Al observar el PIB por sector de actividad, podemos señalar que la actividad del sector primario es más importante en Puebla: entre 2003 y 2014, su participación en el PIв del estado se mantuvo en alrededor de $5 \%$, ligeramente superior a lo que ocurre a nivel nacional, que es de 3\%. En cambio, Baja California mantiene esta participación en el orden de $3 \%$. Mientras que en el sector secundario se observa una tendencia a la baja: para Baja California — del 2003 al 2014 - hay una caída de 38\% a 36\%; en tanto que en Puebla, la baja es de $36 \%$ a 33\%. Estas caídas en la importancia relativa de la actividad industrial podrían ser consecuencia de la crisis económica y su efecto contractivo en las actividades de la industria de la exportación en ambas regiones (Inegi, s.f.).

Si destacamos el comportamiento del sector terciario a lo largo de este periodo, hay un aumento de dos puntos porcentuales para ambas economías, llegando a representar poco más de dos terceras partes del pIB estatal. En suma, tenemos estructuras económicas con ciertas similitudes en cuanto al peso de los sectores productivos, aunque se observa que la actividad agrícola es más importante en Puebla y el sector secundario en Baja California.

En las figuras 1 y 2, se muestra la división territorial de los estados en municipios, siendo Puebla no solamente de mayor extensión sino con una diversidad subregional más marcada. La estructura económica de Puebla es más heterogénea y se encuentra con mayor dispersión en el territorio, el cual está dividido en 217 municipios y siete regiones económicas. En contrastante, Baja California se divide en cinco municipios. Además, el grado de urbanización ${ }^{6}$ en 2010 era de $72 \%$ en Puebla y de $92 \%$ en Baja California, es decir, las actividades económicas tienen un carácter más urbano en este último (cálculos propios a partir de Inegi, 2010).

A fin de dibujar el contexto en el que se elabora esta comparación, es necesario también dimensionar el impacto que tuvieron a nivel nacional y regional, las crisis económicas del 2001 y del 2008. En el 2001, se trató de una crisis que afectó particularmente la actividad productiva de las empresas maquiladoras, en la que se conjugaron tanto el fortalecimiento de China como lugar para la relocalización industrial y como proveedor del mercado estadounidense, así como los cambios en algunos acuerdos del TLCAN, que modificaron las ventajas de México para la operación de empresas extranjeras. Más tarde, en el 2008, se presentó la contracción de la economía de los Estados Unidos por efecto de los desajustes financieros, misma que por su magnitud y por la dependencia de la economía mexicana, generó una contracción del crecimiento anual del PIB de $5.95 \%$ en 2009, con base en precios del 2003 (Aguirre, 2016).

\footnotetext{
${ }^{6}$ El grado de urbanización es el número de habitantes en localidades de más de 2500 habitantes entre la población total por cien.
} 
Figura 1: Muncipios de Baja California

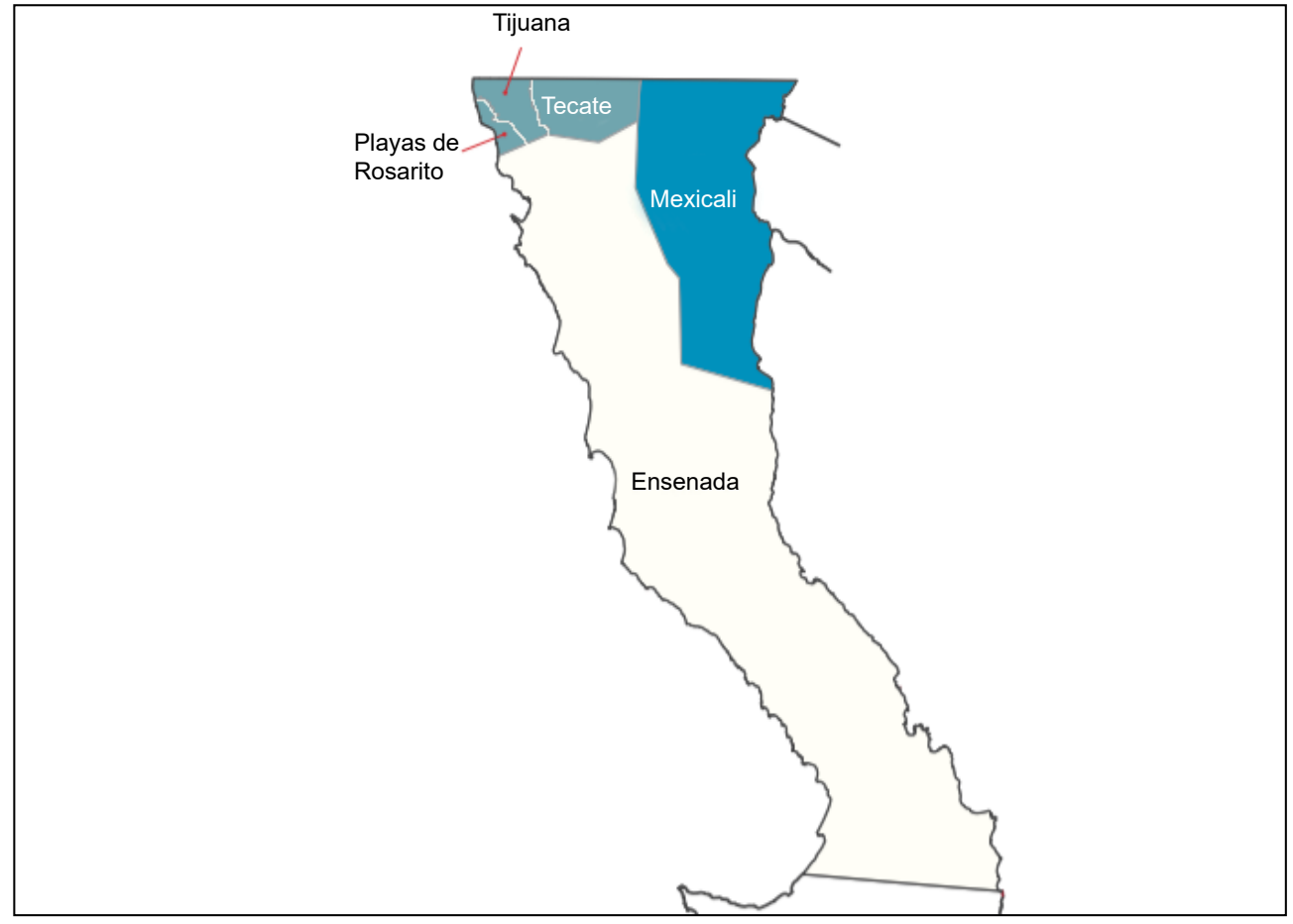

Fuente: Inegi (2014a).

De acuerdo con Ruiz y Ordaz (2011), la economía mexicana no ha generado el número suficiente de empleos (entre uno y 1.2 millones al año) que exige el incremento anual de la población económicamente activa (PEA), por lo que se tiene un déficit importante de empleos. Lo anterior, se refleja en las tasas de desempleo, las cuales se han ubicado entre 3\% y $5 \%$ de la PEA, en los últimos años. Los autores señalan también la convergencia del empleo formal y el informal, ya que cada vez hay más empleos de baja calidad, que carecen de prestaciones sociales y más empleos informales. Es decir, que nos encontramos frente a un panorama de precarización laboral generalizado, tal como lo señalan también Mora y De Oliveira (2010).

\section{El proceso de poblamiento}

En el 2010, el estado de Puebla contaba 5779829 habitantes, casi el doble de población de Baja California, la cual ascendía a 3155070 habitantes. La distribución de la población por edad, nos dice que en Puebla hay un porcentaje ligeramente mayor de menores de quince años (31\% vs. 29\%), los jóvenes (entre 15 y 29 años) representan $27 \%$ en ambas entidades federativas; y los adultos representan $43 \%$ en Baja California y $41 \%$ en Puebla ${ }^{7}$ (Inegi, 2010).

\footnotetext{
${ }^{7}$ La diferencia es por los no especificados.
} 
Figura 2: Municipios de Puebla

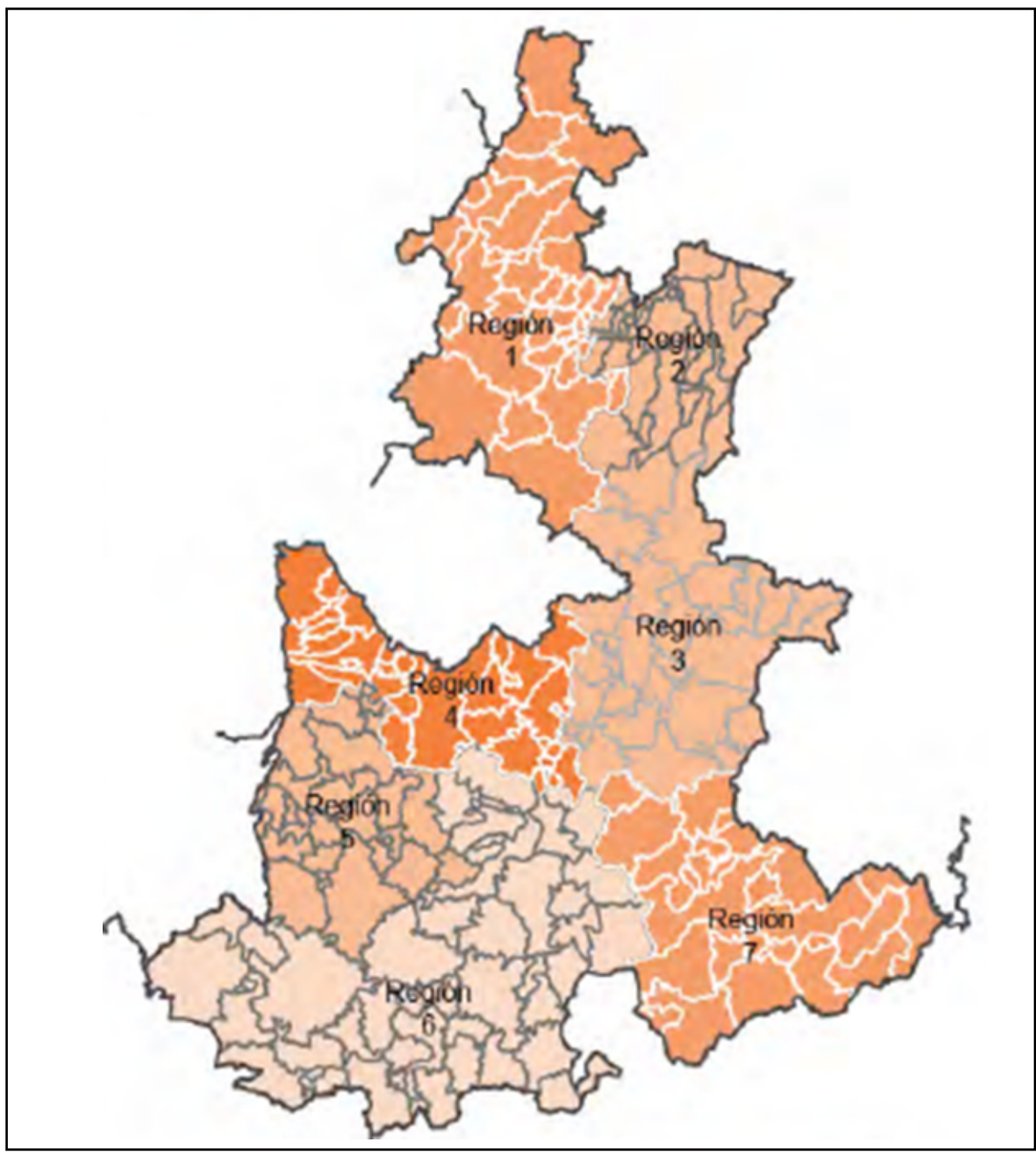

Fuente: Inegi (2014b).

Una de las características que distinguen a estas dos regiones, como fronterizas y no fronterizas, se encuentra relacionada con los procesos de poblamiento. Esto se debe a que las regiones fronterizas del norte de México, se han poblado por la llegada de personas de otros estados del país, mientras que la población de Puebla, como región no fronteriza, tiene una composición mayoritaria de personas nacidas en la entidad (90\%), tal como se puede ver en la Tabla 1; en contraste, en Baja California, los nacidos en la entidad representan solamente la mitad de la población. 
Tabla 1: Distribución porcentual de la población de cinco años y más por condición migratoria, Baja California y Puebla, 2000 y 2010

\begin{tabular}{|l|c|c|c|c|} 
& \multicolumn{2}{c|}{ Baja California } & \multicolumn{2}{c|}{ Puebla } \\
\hline Condición migratoria & $\mathbf{2 0 0 0}$ & $\mathbf{2 0 1 0}$ & $\mathbf{2 0 0 0}$ & $\mathbf{2 0 1 0}$ \\
$\mathbf{\%}$ & $\%$ & 0.9 & 89.5 \\
\hline Nativos & 47.8 & 50.9 & 90.0 & 6.9 \\
\hline Inmigrantes no recientes & 38.9 & 41.2 & 6.5 & 3.4 \\
\hline
\end{tabular}

Fuente: Elaboración propia con datos de Inegi (2010).

En la última década se observan cambios en esta dinámica de crecimiento social. Lo anterior, se puede constatar si atendemos al comportamiento de la inmigración reciente, que se refiere a aquellas personas que llegaron a la entidad durante los cinco años previos al levantamiento del censo. En la Tabla 1, se observa que el porcentaje de esta población disminuyó de $12.8 \%$ a $7.5 \%$ en Baja California, mientras que en Puebla se mantuvo en alrededor de $3 \%$. Este es un cambio significativo en el proceso de poblamiento de Baja California, pues como parte de los efectos de las crisis económicas del 2001 y del 2008, así como del sellamiento de la frontera, dejó de ser polo de atracción de migrantes y redujo su función como lugar de paso de personas con destino en los Estados Unidos, con la consecuente disminución del crecimiento social de la población: la tasa neta de migración correspondiente a $1995-2000$ pasó de $13.2 \%$ a $1.6 \%$ en el siguiente periodo 2005-2010 (Cruz, Silva y Navarro, 2015, p. 181). En el caso de Puebla, las tasas netas de migración ${ }^{8}$ han sido bajas y no presentan cambios tan fuertes en este periodo, de 1995-2000 fue negativa (-.8\%), luego positiva de 2000-2005 (0.2\%) y en 2005-210 negativa $(-0.2 \%)$, es decir, que ha sido un estado expulsor moderado de población (Cruz et al., 2015, p. 181).

En las últimas décadas, observamos otros procesos ligados también a la contracción del crecimiento económico y a la política migratoria de los Estados Unidos y que han significado el retorno (voluntario o forzado - deportados-) de mexicanos provenientes de este país.

\section{Una caracterización de los mercados de trabajo}

Esta sección se desarrrolló en cuatro apartados, cada uno de ellos se ocupa de distintas dimensiones que permiten identificar las diferencias regionales en los perfiles de los mercados de trabajo y en sus cambios, durante la década 2000-2010. Los apartados son los siguientes: Dinámica y composición, Estructura de los mercados de trabajo, Ingresos laborales, y Segregación ocupacional por condición migratoria y sexo.

\footnotetext{
${ }^{8}$ La tasa neta de migración es la diferencia entre inmigrantes y emigrantes, entre la población total.
} 


\section{Dinámica y composición}

Durante la última década del presente siglo, la dinámica de crecimiento del empleo ha sido lenta a consecuencia de las crisis económicas que se presentaron en 2001 y 2008. En Baja California, que por mucho tiempo se consideró como un lugar de oportunidades por las bajas tasas de desempleo, se han presentado tasas de desempleo sin precedentes (para el último trimestre del año las tasas fueron $6.69 \%$ en $2009,6.79 \%$ en $2011,5.1 \%$ en 2013 y $3.74 \%$ en 2015 ), cuando antes del 2007 se había mantenido por debajo del 2.5\% (Inegi, 2011a). En gran medida, la pérdida de empleos se debió a la contracción ocurrida en la demanda de empleo de las empresas maquiladoras de exportación.

En contraste, los niveles de desempleo en Puebla fueron menos dramáticos que en Baja California, aunque registraron un pico en 2011 y en los últimos años bajaron significativamente $3.6 \%$ en 2009, $4.8 \%$ en 2011 , 3.76\% en 2013 y $3.03 \%$ en 2015 (Inegi, 2011b; 2016a), mostrando su menor dependencia del exterior.

La composición de los mercados de trabajo según la condición migratoria (nativos, migrantes no recientes y migrantes recientes), tiene correspondencia con las características descritas en el apartado anterior. Por lo que la población ocupada en ambas entidades se distribuye en las categorías señaladas de la siguiente manera: el 88\% de nativos en Puebla se mantiene en 2000 y 2010; en Baja California aumenta ligeramente de $40 \%$ a $42 \%$, y el dato más relevante de la Tabla 2 es la disminución del porcentaje de la población ocupada de reciente inmigración en este estado, que pasó de $15 \%$ en 2000 a $8 \%$ en 2010.

Tabla 2: Distribución porcentual de la población ocupada según condición migratoria, 2000 y 2010

\begin{tabular}{|c|c|c|c|c|c|c|}
\hline \multirow{3}{*}{ Entidad } & \multicolumn{3}{|c|}{$\begin{array}{c}2000 \\
(\%)\end{array}$} & \multicolumn{3}{|c|}{$\begin{array}{c}2010 \\
(\%)\end{array}$} \\
\hline & Nativos & Inmi & ntes & Nativos & Inmig & ates \\
\hline & & No reciente & Reciente & & No reciente & Reciente \\
\hline Baja California & 40 & 45 & 15 & 42 & 50 & 8 \\
\hline Puebla & 88 & 8 & 4 & 88 & 8 & 4 \\
\hline
\end{tabular}

Fuente: Elaboración propia con datos de Inegi (2010).

La incorporación de las mujeres al trabajo remunerado del 2001 al 2010 ha sido más intensiva en Baja California, lo cual se refleja en una mayor proporción de mujeres como parte de la población ocupada, ampliándose el porcentaje de diferencia entre las dos entidades en 5\% para el 2010, cuando las mujeres representaron $37 \%$ de la población ocupada en Baja California y $32 \%$ en Puebla (Tabla 3). 
Tabla 3: Distribución porcentual de la población ocupada según sexo, 2000 y 2010

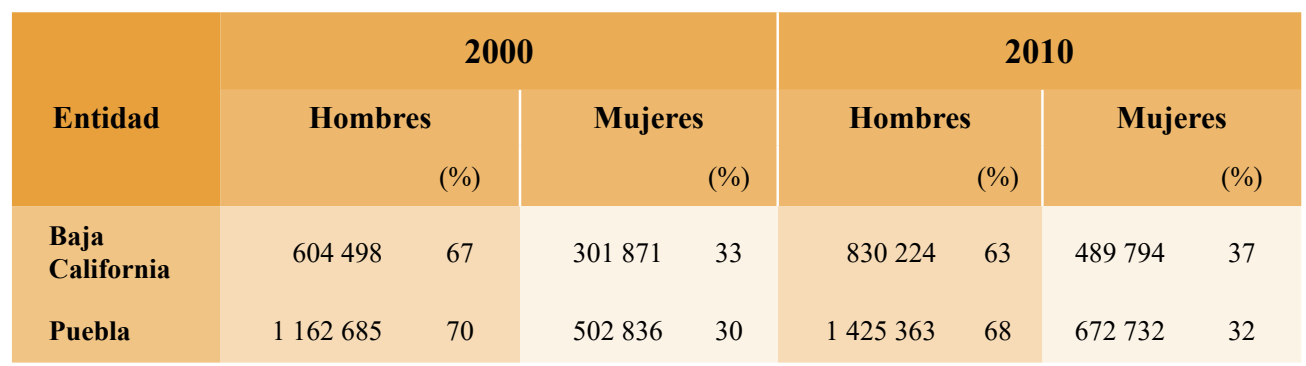

Fuente: Elaboración propia con datos de Inegi (2010).

\section{Estructura de los mercados de trabajo}

La descripción de la estructura de los mercados de trabajo se refiere a la distribución de los empleos según la forma de absorción de la fuerza de trabajo, es decir, a los niveles de salarización de la población ocupada. En México persiste una heterogeneidad estructural, que se expresa de diferente manera en las regiones fronterizas y no fronterizas, resultando una estructura ocupacional también heterogénea. En las regiones fronterizas del norte de México, se observa una mayor salarización de la fuerza de trabajo, con la consecuente formalización de las relaciones de trabajo y mayor acceso a las prestaciones sociales, mientras que en regiones del centro del país, como Puebla, la formalización de las relaciones de trabajo es menos extendida, y persisten formas productivas que podrían denominarse atípicas, en las que se observa una mayor presencia de población indígena en localidades rurales.

En la Tabla 4 se presenta la distribución de la PEA ocupada para el primer semestre del 2016, según las categorías: trabajadores independientes (empleadores y por cuenta propia), trabajadores subordinados (trabajadores subordinados y remunerados, asalariados y con percepciones no salariales) y trabajadores no remunerados (familiares sin pago y no familiares sin pago). Al mismo tiempo, se clasifica a la población ocupada por sexo y entidad federativa.

Tabla 4: Distribución porcentual de la población ocupada según posición en la ocupación y sexo, primer trimestre de 2016

\begin{tabular}{|c|c|c|c|c|}
\hline \multirow{3}{*}{$\begin{array}{l}\text { Posición en la } \\
\text { ocupación }\end{array}$} & \multicolumn{2}{|c|}{ Hombres } & \multicolumn{2}{|c|}{ Mujeres } \\
\hline & Baja California & Puebla & Baja California & Puebla \\
\hline & $(\%)$ & $(\%)$ & $(\%)$ & $(\%)$ \\
\hline $\begin{array}{l}\text { Trabajadores } \\
\text { independientes }\end{array}$ & 22 & 32 & 18 & 25 \\
\hline $\begin{array}{l}\text { Trabajadores } \\
\text { subordinados }\end{array}$ & 77 & 63 & 79 & 62 \\
\hline $\begin{array}{l}\text { Trabajadores no } \\
\text { remunerados }\end{array}$ & 1 & 6 & 3 & 13 \\
\hline Total & 100 & 100 & 100 & 100 \\
\hline
\end{tabular}

Fuente: Elaboración propia a partir de datos de la Enoe (Inegi, 2016a). 
La distribución expresa las diferencias señaladas, en lo que respecta a la persistencia del trabajo independiente (empleadores y por cuenta propia) en el estado de Puebla, tanto para hombres como para las mujeres, aunque la diferencia más notoria es en el porcentaje de hombres que son no asalariados. Otro indicador de la menor salarización y la persistencia de formas tradicionales de producción es la importancia relativa del trabajo no remunerado en Puebla, sobre todo, entre las mujeres (13\%); este dato se encuentra relacionado con la importancia de las actividades agrícolas y la tradición del trabajo de las mujeres como familiares sin pago. Tal situación, se refleja en la proporción de mujeres ocupadas en el sector primario en Puebla, que llega a 9\%, mientras que en Baja California es 5\% (Inegi, 2016a).

Las diferencias en la proporción de trabajadores subordinados, confirman que el trabajo asalariado y remunerado en Baja California se encuentra más extendido, cuya proporción está 10 puntos porcentuales por encima del correspondiente a Puebla, y es más evidente entre las mujeres. Esta distribución nos informa de un mayor avance de la incorporación de las mujeres al trabajo asalariado en Baja California y de una situación de mayor equilibrio en la participación en los mercados de trabajo entre hombres y mujeres. El porcentaje de mujeres ocupadas en el sector secundario en Baja California, para el primer trimestre del 2016, es de 27\% y el de Puebla de 16\%; sin embargo, es preciso advertir que la participación femenina en el trabajo remunerado no necesariamente significa una menor desigualdad entre hombres y mujeres. Otro indicador de la presencia de mujeres en trabajos que pudieran ser no asalariados o precarios, es la participación en la ocupación en el sector terciario (comercio y servicios): en Puebla asciende a 74\%, mientras que en Baja California a 66\% (Tabla 5).

Tabla 5: Distribución de la población ocupada según sector de actividad y sexo, primer semestre de 2016

\begin{tabular}{|c|c|c|c|c|}
\hline \multirow[b]{2}{*}{$\begin{array}{l}\text { Sector de } \\
\text { actividad }\end{array}$} & \multicolumn{2}{|c|}{ Hombres } & \multicolumn{2}{|c|}{ Mujeres } \\
\hline & Baja California & Puebla & Baja California & Puebla \\
\hline & $\%$ & $\%$ & $\%$ & $\%$ \\
\hline Primario & 7 & 30 & 5 & 9 \\
\hline Secundario & 35 & 27 & 27 & 16 \\
\hline Terciario & 52 & 42 & 66 & 74 \\
\hline No especificado & 6 & 0 & 2 & 0 \\
\hline Total & 100 & 100 & 100 & 100 \\
\hline
\end{tabular}

Fuente: Elaboración propia a partir de datos de la Enoe (Inegi, 2016a).

Entre los hombres, la diferencia más notoria es el porcentaje que se ocupa en el sector primario, que en Puebla es de 30\% frente a 7\% en Baja California. En el sector secundario tenemos que $27 \%$ de los hombres poblanos se ocupan en actividades de este sector, y 35\% lo hace en Baja California. En el comercio y servicios (sector terciario) laboran $42 \%$ en Puebla y 52\% en Baja California (Tabla 5). 
A fin de mostrar las diferencias en la estructura ocupacional, son particularmente útiles las figuras 3a, 3b, 4a y 4b que nos muestran las unidades económicas de cada entidad federativa clasificadas según el tamaño (micro, pequeñas, medianas y grandes) y su participación en la generación de ingresos estatales. La diferencia entre una y otra entidad federativa, reside en que en Baja California el porcentaje de unidades económicas micro (de 0 a 10 personas ocupadas) es ligeramente inferior que en Puebla (92.1\% vs. 97\%, ver Figura 3a y Figura 4a), su contribución al PIB estatal es de $17.1 \%$ en Baja California y 13.5\% en Puebla. Las principales actividades productivas de las unidades micro para ambas entidades son los abarrotes y alimentos al por menor y preparación de alimentos y bebidas, en tercer lugar se encuentra la reparación de automóviles en Baja California y las panaderías y tortillerías en Puebla (Inegi, 2014a; 2014b).

Figura 3a: Baja California. Unidades económicas según tamaño y participación en los ingresos totales estatales, 2013

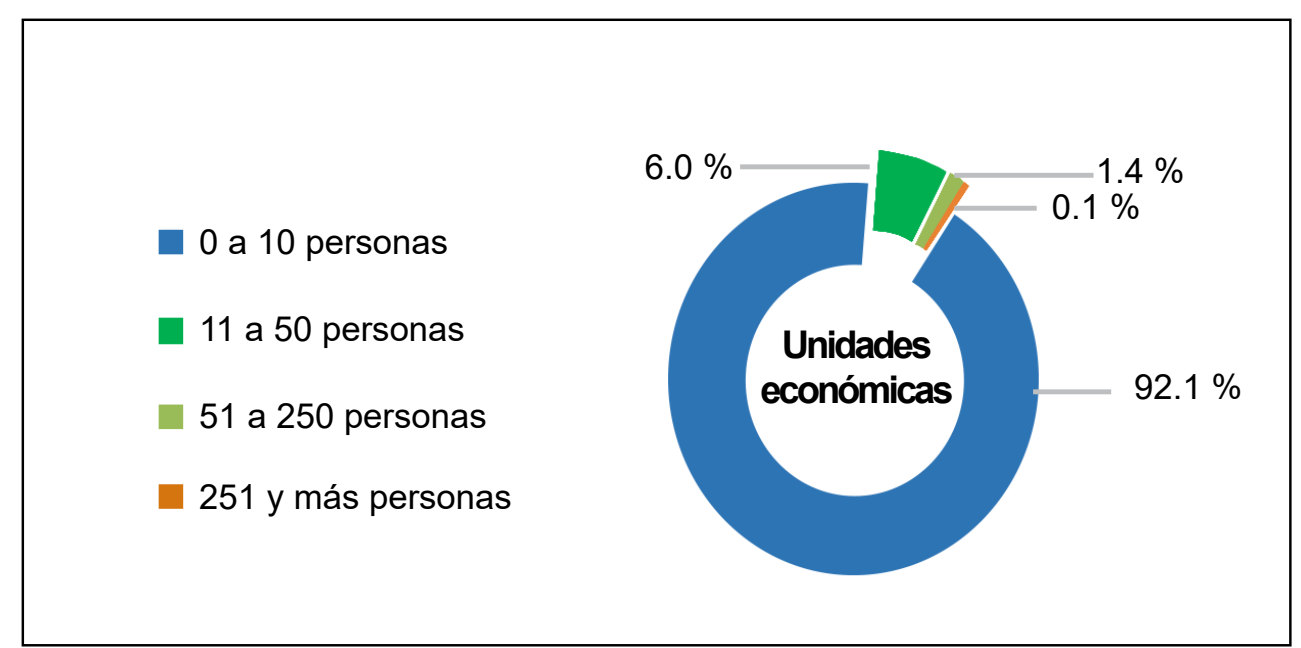

Fuente: Inegi (2014a).

Figura 3b: Baja California. Unidades económicas según tamaño y participación en los ingresos totales estatales, 2013

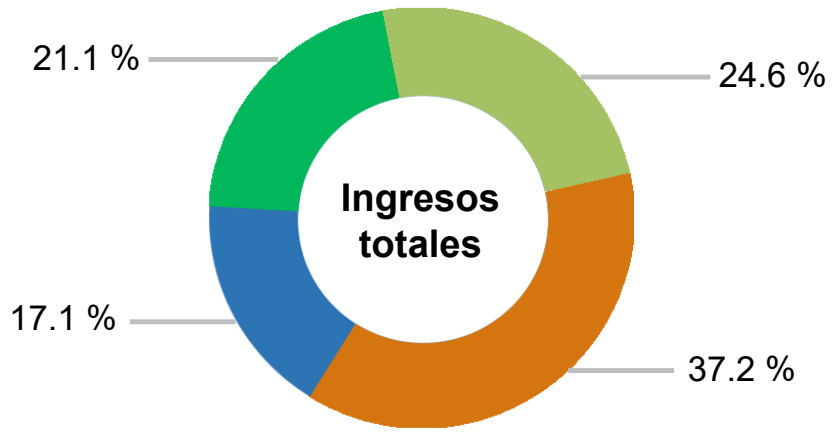

Fuente: Inegi (2014a). 
Figura 4a: Puebla. Unidades económicas según tamaño y participación en los ingresos totales estatales, 2013

0 a 10 personas

11 a 50 personas

51 a 250 personas

251 y más personas

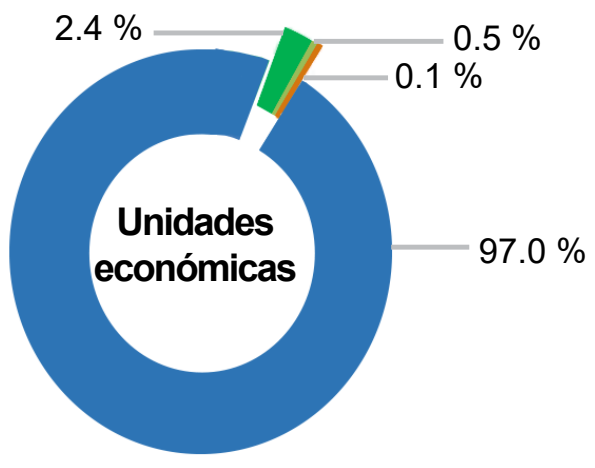

Fuente: Inegi (2014b).

Figura 4b: Puebla. Unidades económicas según tamaño y participación en los ingresos totales estatales, 2013

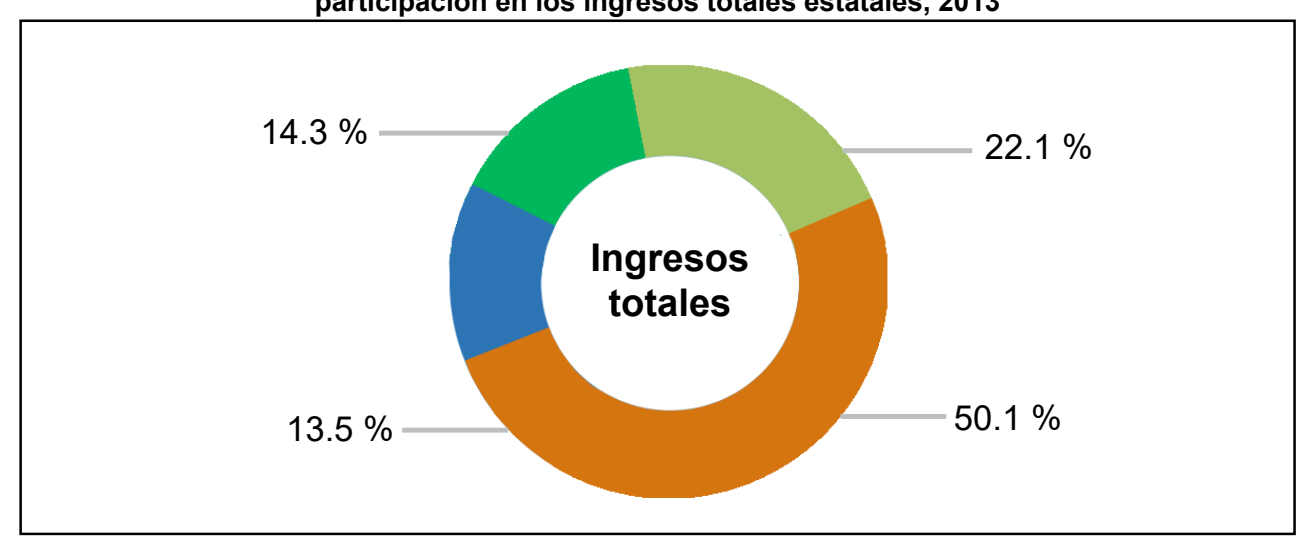

Fuente: Inegi (2014b).

Las pequeñas unidades económicas (11 a 50 personas) y las medianas (51 a 250 personas) representan una proporción mayor en Baja California (7.4\% contra 2.9\% en Puebla, ver Figura 3a y Figura 4a), y tienen una contribución al piB estatal también mayor ( $45.7 \%$ contra $36.4 \%$, ver figuras $3 \mathrm{~b}$ y $4 \mathrm{~b}$ ). Mientras que las unidades grandes (más de 250 personas ocupadas) solamente representan $0.1 \%$ en ambas economías pero generan $37.2 \%$ del PIB estatal en Baja California y $50.1 \%$ en Puebla, siendo las principales actividades económicas en ambas la fabricación de automóviles y camiones. En menor proporción se destacan la fabricación de equipo no electrónico dental y oftálmico, la industria de la bebida, y la fabricación de equipo de audio y video y componentes electrónicos, en Baja California, mientras que en Puebla son la fabricación de partes de automóviles, y las telecomunicaciones inalámbricas, 
producción de petróleo y gas, chocolates, dulces, conservación de frutas, y verduras (Inegi, 2014a; 2014b).

Estos datos nos permiten señalar que hay una polarización de la estructura productiva en Puebla, por la importancia de las microunidades y la participación en el PIB estatal de las grandes empresas. En cambio, en Baja California, tienen una participación importante en la estructura productiva las pequeñas y medianas unidades económicas. En cuanto a la vocación económica, el sector automotriz en ambos territorios es preponderante, aunque es notoria también la presencia de otros sectores en Baja California como la fabricación de productos electrónicos y médicos.

Otros indicadores que dan cuenta de un mercado de trabajo más heterogéneo en Puebla y con empleos de menor calidad, se consignan en la Tabla 6. Las tasas de ocupación parcial y desocupación y de subocupación (entendida esta como la necesidad de trabajar más tiempo, lo que se traduce en la búsqueda de una ocupación complementaria o de un nuevo trabajo con mayor horario) tienen mayor incidencia en Puebla que en Baja California. La tasa de las condiciones críticas de ocupación se refiere al porcentaje de la población ocupada que se encuentra trabajando menos de 35 horas a la semana por razones del mercado de trabajo, junto con la que trabaja más de 35 horas semanales con ingresos mensuales inferiores al salario mínimo y la que labora más de 48 horas semanales ganando hasta dos salarios mínimos. Se trata de la población ocupada que labora en condiciones más precarias y su crecimiento confirma la caída en la calidad de los empleos. Este indicador es casi tres veces más alto en Puebla, pero en Baja California, el aumento de esta tasa en los últimos 10 años ha sido muy rápido, pasó de $2.1 \%$ a $7.7 \%$ (Levar, 2011).

Tabla 6: Indicadores de la ocupación por entidad federativa durante el primer trimestre de 2016

\begin{tabular}{|c|c|c|c|c|c|c|c|}
\hline Entidad & $\begin{array}{c}\text { Ocupación } \\
\text { parcial y } \\
\text { desocupación } \\
\%\end{array}$ & $\begin{array}{c}\text { Presión } \\
\text { general }^{2 /} \\
\%\end{array}$ & $\begin{array}{c}\text { Trabajo } \\
\text { asalariado }^{3 /} \\
\%\end{array}$ & $\underset{\%}{\text { Subocupación }^{3 /}}$ & $\begin{array}{c}\text { Condiciones } \\
\text { críticas de } \\
\text { ocupación }^{3 /} \\
\%\end{array}$ & $\begin{array}{c}\text { Informalidad } \\
\text { laboral }^{3 /} \\
\%\end{array}$ & $\begin{array}{c}\text { Ocupación } \\
\text { en el sector } \\
\text { informal }^{3 /} \\
\%\end{array}$ \\
\hline Nacional & 10.2 & 7.9 & 64.5 & 7.9 & 14 & 57.4 & 27.1 \\
\hline $\begin{array}{l}\text { Baja } \\
\text { California }\end{array}$ & 6.5 & 4.7 & 72.4 & 2.7 & 7.7 & 41.4 & 19.9 \\
\hline Puebla & 10 & 6.7 & 56.6 & 6.1 & 20.7 & 73.3 & 31.8 \\
\hline
\end{tabular}

1/ Tasa calculada respecto a la población en edad de trabajar.

2/ Tasas calculadas respecto a la población económicamente activa.

3/ Tasas calculadas respecto a la población ocupada.

Fuente: A partir de Inegi (2016b).

La tasa de ocupación en el sector informal se refiere a la población ocupada en una unidad económica que opera a partir de los recursos del hogar, pero sin constituirse como empresa, de tal suerte que la actividad no tiene una situación identificable e independiente de ese hogar. En Puebla asciende a 31.8\% y en Baja California a 19.9\%, la primera cifra se encuentra por arriba de lo que ocurre a nivel nacional $(27.1 \%)$ mientras que la segunda se encuentra por debajo de este promedio. 
Al considerar una medición ampliada de la ocupación informal, es decir, la tasa de informalidad laboral ${ }^{9}$ es posible observar una brecha más grande entre los datos correspondientes a Puebla y Baja California, encontrándose en esta situación 73.3\% contra $41.4 \%$ de la población ocupada, respectivamente.

\section{Ingresos laborales}

Un indicador que es útil para mostrar qué tanto se tiene acceso a un ingreso justo a través de los salarios recibidos por el trabajo, es el Índice de la tendencia laboral de la pobreza (ITLP), que elabora el Coneval. Este índice tiene dos componentes - los salarios y los precios de la canasta básica- y es una medida del poder adquisitivo del ingreso laboral que muestra la tendencia del porcentaje de personas que no puede adquirir la canasta alimentaria con el ingreso laboral. Por lo tanto, si el ITLP aumenta, significa que es mayor el porcentaje de personas que no pueden comprar una canasta alimentaria con su ingreso laboral.

En la figuras 5 y figura 6, podemos observar que, del 2005 al 2015, el estado de Baja California tuvo una drástica caída del poder adquisitivo del ingreso laboral, al aumentar el ITLP más del doble, al pasar de 0.65 a cerca de 1.6 en diez años; mientras que el comportamiento del ITLP para Puebla es más estable en este periodo, pero también da cuenta de un deterioro en los ingresos laborales, oscilando el ITLP de 0.85 a 1.1 en el mismo periodo.

Figura 5: Baja California. Índice de la tendencia laboral de la pobreza*, 2005-2015

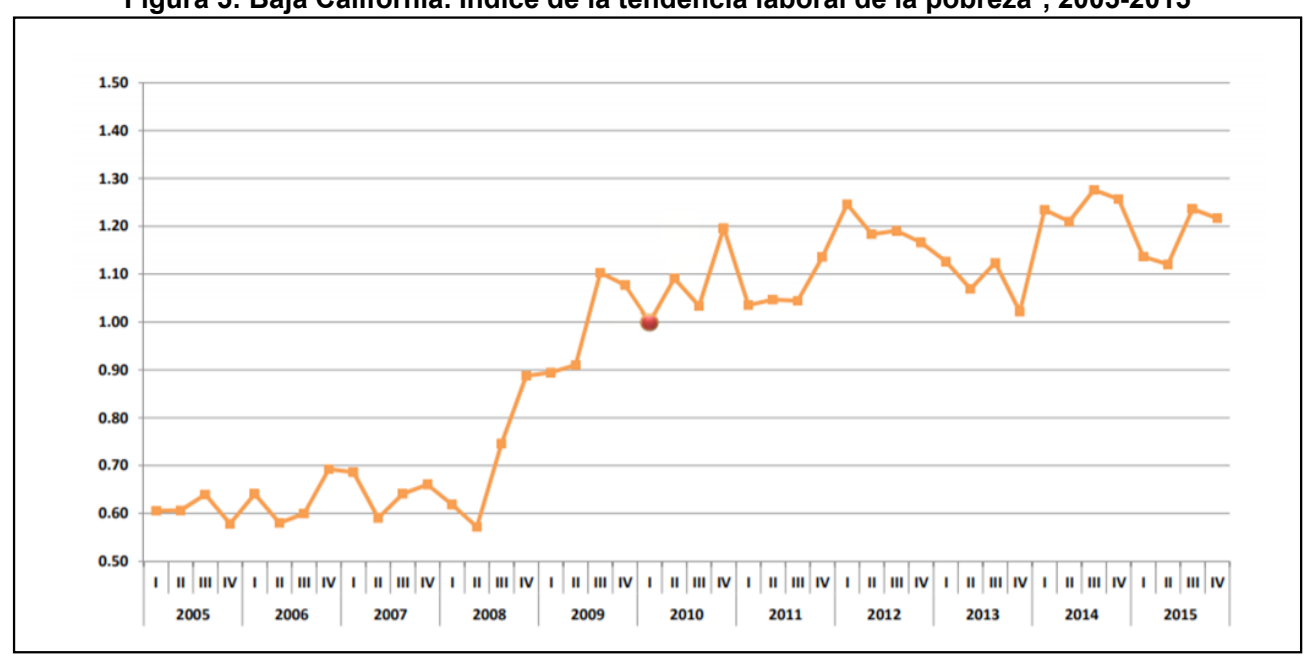

*Base primer trimestre 2010.

Fuente: Coneval, 2016.

${ }^{9}$ La tasa de informlidad laboral "añade a la definición de trabajo informal las siguientes categorías: el trabajo no protegido en la actividad agropecuaria, el servicio doméstico remunerado de los hogares, así como los trabajadores subordinados que, aunque trabajan para unidades económicas formales, lo hacen bajo modalidades en las que se elude el registro ante la seguridad social" (Inegi, 2016b, p. 9). 
Figura 6: Puebla. Índice de la tendencia laboral de la pobreza*, 2005-2015

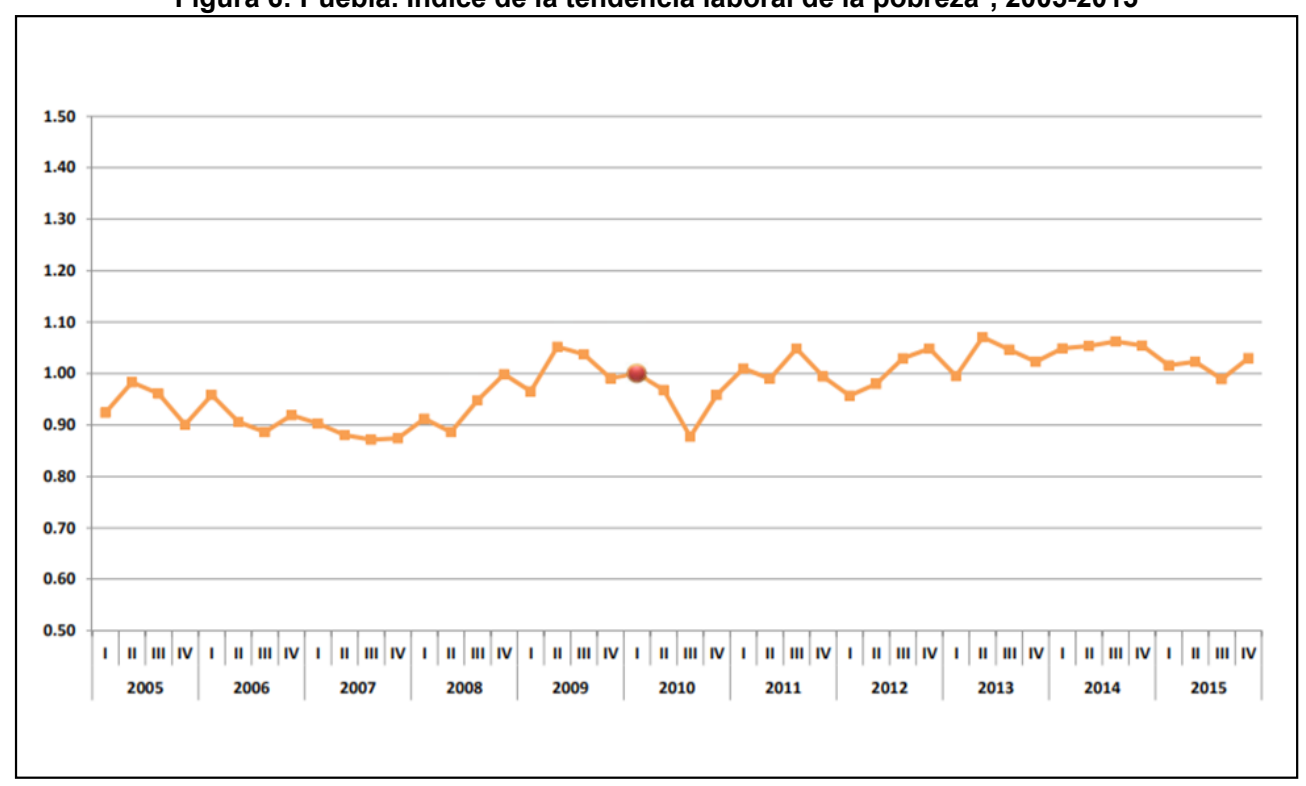

*Base primer trimestre 2010.

Fuente: Coneval, 2016.

Lo que nos informan estos datos es que el proceso de precarización del empleo por el componente salarial es más notorio en Baja California, que en Puebla, debido al impacto de las crisis económicas, del 2001 y 2008, y de la mayor dependencia de la economía local respecto a los cambios en el contexto internacional.

\section{Segregación ocupacional por condición migratoria y sexo}

Con el objetivo de analizar la segregación de la población según su condición migratoria y el sexo, hemos identificado las 10 principales ocupaciones de la población económicamente activa en 2010. A partir de esta información se observa que, en términos de ocupaciones, en Baja California la población migrante no reciente y reciente presentan diferencias importantes respecto a la población nativa. Destacan las ocupaciones de vigilantes y guardias en establecimientos y trabajadores domésticos, como parte de las ocupaciones principales de la población inmigrante, así como la ocupación de trabajadores de apoyo a la construcción, en el caso de migrantes recientes. La ocupación de ensambladores y montadores de partes eléctricas y electrónicas se encuentra entre las 10 principales ocupaciones de nativos e inmigrantes, lo cual indica la importancia del empleo en este sector de actividad en el estado, lo mismo se puede interpretar de la ocupación de comerciante en establecimientos (Tabla 7). 
Tabla 7: Baja California. 10 principales ocupaciones de la PEA por condición migratoria, 2010

\begin{tabular}{|c|c|c|}
\hline Nativos & Inmigrantes no recientes & Migrantes recientes \\
\hline $\begin{array}{l}\text { Empleados de ventas, } \\
\text { despachadores y } \\
\text { dependientes de comercio. }\end{array}$ & $\begin{array}{l}\text { Comerciantes en } \\
\text { establecimientos. }\end{array}$ & $\begin{array}{l}\text { Trabajadores de apoyo } \\
\text { en actividades agrícolas. }\end{array}$ \\
\hline $\begin{array}{l}\text { Comerciantes en } \\
\text { establecimientos. }\end{array}$ & $\begin{array}{l}\text { Empleados de ventas, } \\
\text { despachadores y } \\
\text { dependientes en comercios. }\end{array}$ & $\begin{array}{l}\text { Albañiles, mamposteros } \\
\text { y afines. }\end{array}$ \\
\hline $\begin{array}{l}\text { Albañiles, mamposteros y } \\
\text { afines. }\end{array}$ & $\begin{array}{l}\text { Albañiles, mamposteros y } \\
\text { afines. }\end{array}$ & $\begin{array}{l}\text { Ensambladores y } \\
\text { montadores de partes } \\
\text { eléctricas y electrónicas. }\end{array}$ \\
\hline $\begin{array}{l}\text { Mecánicos en } \\
\text { mantenimientos y reparación } \\
\text { de vehículos de motor. }\end{array}$ & $\begin{array}{l}\text { Trabajadores de apoyo en } \\
\text { actividades agrícolas. }\end{array}$ & $\begin{array}{l}\text { Empleados de ventas, } \\
\text { despachadores y } \\
\text { dependientes de } \\
\text { comercios. }\end{array}$ \\
\hline $\begin{array}{l}\text { Conductores de camiones, } \\
\text { camionetas y automóviles } \\
\text { de carga. }\end{array}$ & $\begin{array}{l}\text { Vigilantes y guardias en } \\
\text { establecimientos. }\end{array}$ & $\begin{array}{l}\text { Vigilantes en } \\
\text { establecimientos. }\end{array}$ \\
\hline Secretarias. & Trabajadores domésticos. & $\begin{array}{l}\text { Trabajadores } \\
\text { domésticos. }\end{array}$ \\
\hline $\begin{array}{l}\text { Barrenderos y trabajadores } \\
\text { de limpieza (excepto en } \\
\text { hoteles y restaurantes. }\end{array}$ & $\begin{array}{l}\text { Supervisores de operadores } \\
\text { de maquinaria industrial. }\end{array}$ & $\begin{array}{l}\text { Cajeros, taquilleros y } \\
\text { receptores de apuestas. }\end{array}$ \\
\hline $\begin{array}{l}\text { Cajeros, taquilleros y } \\
\text { receptores de apuestas. }\end{array}$ & $\begin{array}{l}\text { Mecánicos en mantenimiento } \\
\text { y reparación de vehículos de } \\
\text { motor. }\end{array}$ & $\begin{array}{l}\text { Trabajadores de apoyo } \\
\text { en la construcción. }\end{array}$ \\
\hline $\begin{array}{l}\text { Ensambladores y montadores } \\
\text { de partes eléctricas y } \\
\text { electrónicas. }\end{array}$ & $\begin{array}{l}\text { Vendedores ambulantes } \\
\text { de artículos diversos } \\
\text { (excluyendo los de venta de } \\
\text { alimentos). }\end{array}$ & $\begin{array}{l}\text { Conductores autobuses, } \\
\text { camiones, camionetas, } \\
\text { taxi y automóviles de } \\
\text { pasajeros. }\end{array}$ \\
\hline
\end{tabular}

Fuente: Elaboración propia con datos de la muestra censal de Inegi (2010).

En contraste, en Puebla, no pareciera tan evidente la segregación ocupacional según condición migratoria, ya que hay varias ocupaciones que se clasifican como principales para las tres categorías de población, aunque la categoría ocupacional de vendedores ambulantes de artículos diversos (excluyendo los de venta de alimentos), pareciera presentar cierta concentración entre la población inmigrante. En el caso de inmigrantes recientes podrían ocuparse con cierta recurrencia como vigilantes y guardias en establecimientos o en la elaboración de pan, tortilla, repostería, y otros productos de cereales y harinas. Resalta para esta entidad que entre las 10 ocupaciones más importantes para la población nativa, tres están asociadas con el sector agrícola y la principal es la de trabajadores en el cultivo de maíz y/o frijol (Tabla 8). Aunque no hemos considerado la diferencia entre población indígena y no indígena, muy posiblemente se exprese en las ocupaciones una segregación por el origen étnico. 
Asimismo, hay varias ocupaciones principales e independientes de la condición migratoria, aquellas que pertenecen al sector terciario (en particular al comercio), y la de operadores de máquinas de costura, bordado y de corte para la confección de productos textiles y prendas de vestir. Estos empleos son ofrecidos por empresas maquiladoras para la exportación, sobre todo, en el Valle de Tehuacán.

Tabla 8: Puebla. 10 principales ocupaciones de la PEA por condición migratoria, 2010

\begin{tabular}{|c|c|c|}
\hline Nativos & $\begin{array}{l}\text { Inmigrantes no } \\
\text { recientes }\end{array}$ & Migrantes recientes \\
\hline $\begin{array}{l}\text { Trabajadores en el cultivo de } \\
\text { maíz y/o frijol. }\end{array}$ & $\begin{array}{l}\text { Comerciantes en } \\
\text { establecimientos. }\end{array}$ & $\begin{array}{l}\text { Comerciantes en } \\
\text { establecimientos. }\end{array}$ \\
\hline $\begin{array}{l}\text { Comerciantes en } \\
\text { establecimientos. }\end{array}$ & $\begin{array}{l}\text { Empleados de ventas, } \\
\text { despachadores y } \\
\text { dependientes en comercio. }\end{array}$ & $\begin{array}{l}\text { Empleados de ventas, } \\
\text { despachadores y } \\
\text { dependientes en comercio. }\end{array}$ \\
\hline $\begin{array}{l}\text { Empleados de ventas, } \\
\text { despachadores y dependientes } \\
\text { en comercio. }\end{array}$ & $\begin{array}{l}\text { Albañiles, mamposteros y } \\
\text { afines. }\end{array}$ & $\begin{array}{l}\text { Vigilantes y guardias en } \\
\text { establecimientos. }\end{array}$ \\
\hline $\begin{array}{l}\text { Albañiles, mamposteros y } \\
\text { afines. }\end{array}$ & $\begin{array}{l}\text { Otros especialistas no } \\
\text { clasificados anteriormente. }\end{array}$ & $\begin{array}{l}\text { Albañiles, mamposteros y } \\
\text { afines. }\end{array}$ \\
\hline $\begin{array}{l}\text { Otros trabajadores en } \\
\text { actividades agrícolas no } \\
\text { clasificados anteriormente. }\end{array}$ & Trabajadores domésticos. & $\begin{array}{l}\text { Trabajadores en la } \\
\text { elaboración de pan, } \\
\text { tortilla, repostería, y otros } \\
\text { productos de cereales y } \\
\text { harinas. }\end{array}$ \\
\hline Trabajadores domésticos. & $\begin{array}{l}\text { Operadores de máquinas } \\
\text { de costura, bordado y de } \\
\text { corte para la confección de } \\
\text { productos textiles y prendas } \\
\text { de vestir. }\end{array}$ & $\begin{array}{l}\text { Vendedores ambulantes } \\
\text { de artículos diversos } \\
\text { (excluyendo los de venta de } \\
\text { alimentos). }\end{array}$ \\
\hline $\begin{array}{l}\text { Operadores de máquinas } \\
\text { de costura, bordado y de } \\
\text { corte para la confección de } \\
\text { productos textiles y prendas } \\
\text { de vestir. }\end{array}$ & $\begin{array}{l}\text { Barrenderos y trabajadores } \\
\text { de limpieza (excepto en } \\
\text { hoteles y restaurantes). }\end{array}$ & Trabajadores domésticos. \\
\hline $\begin{array}{l}\text { Trabajadores de apoyo en la } \\
\text { construcción. }\end{array}$ & $\begin{array}{l}\text { Vendedores ambulantes } \\
\text { de artículos diversos } \\
\text { (excluyendo los de venta de } \\
\text { alimentos). }\end{array}$ & $\begin{array}{l}\text { Agentes y representantes de } \\
\text { venta y consignatarios. }\end{array}$ \\
\hline $\begin{array}{l}\text { Conductores de autobuses, } \\
\text { camiones, camionetas, taxis y } \\
\text { automóviles de pasajeros. }\end{array}$ & $\begin{array}{l}\text { Conductores de autobuses, } \\
\text { camiones, camionetas, taxis } \\
\text { y automóviles de pasajeros. }\end{array}$ & $\begin{array}{l}\text { Operadores de máquinas } \\
\text { de costura, bordado y de } \\
\text { corte para la confección de } \\
\text { productos textiles y prendas } \\
\text { de vestir. }\end{array}$ \\
\hline $\begin{array}{l}\text { Trabajadores de apoyo en } \\
\text { actividades agrícolas. }\end{array}$ & $\begin{array}{l}\text { Profesores de enseñanza } \\
\text { primaria. }\end{array}$ & $\begin{array}{l}\text { Conductores de autobuses, } \\
\text { camiones, camionetas, taxis } \\
\text { y automóviles de pasajeros. }\end{array}$ \\
\hline
\end{tabular}

Fuente: Elaboración propia con datos de la muestra censal de Inegi (2010). 
Si hacemos una lectura de la Tabla 9, que resume las 10 principales ocupaciones según el sexo, en Baja California, se puede señalar que las ocupaciones de ensamble de electrónicos, trabajo doméstico, cajeras, taquilleras y recepcionistas de apuestas, secretarias, vendedoras ambulantes, operadoras de máquinas industriales o barrenderas se encuentran feminizadas, mientras que los hombres tienden a concentrarse en ocupaciones tales como albañiles, mamposteros y afines, como vigilantes y guardias en establecimientos, como mecánicos en mantenimiento y reparación de vehículos de motor y como conductores y otras ocupaciones relacionadas con la industria.

Tabla 9: Baja California. 10 principales ocupaciones de la PEA según sexo, 2010

\begin{tabular}{|c|c|}
\hline Hombres & Mujeres \\
\hline Albañiles, mamposteros y afines. & Comerciantes en establecimientos. \\
\hline Trabajadores de apoyo en actividades agrícolas. & $\begin{array}{l}\text { Empleados de ventas, despachadores y } \\
\text { dependientes en comercios. }\end{array}$ \\
\hline $\begin{array}{l}\text { Empleados de ventas, despachadores y dependientes } \\
\text { en comercios. }\end{array}$ & Trabajadores domésticos. \\
\hline Comerciantes en establecimientos. & $\begin{array}{l}\text { Ensambladores y montadores de partes } \\
\text { eléctricas y electrónicas. }\end{array}$ \\
\hline $\begin{array}{l}\text { Mecánicos en mantenimientos y reparación de } \\
\text { vehículos de motor. }\end{array}$ & Cajeros, taquilleros y receptores de apuestas. \\
\hline Vigilantes y guardias en establecimientos. & Secretarias. \\
\hline $\begin{array}{l}\text { Conductores de camiones, camionetas y automóviles } \\
\text { de carga. }\end{array}$ & $\begin{array}{l}\text { Vendedores ambulantes de artículos diversos } \\
\text { (excluyendo los de venta de alimentos). }\end{array}$ \\
\hline $\begin{array}{l}\text { Conductores de autobuses, camiones, camionetas, } \\
\text { taxis y automóviles de pasajeros. }\end{array}$ & $\begin{array}{l}\text { Otros operadores de maquinaria industrial, } \\
\text { ensambladores y conductores de transporte. }\end{array}$ \\
\hline $\begin{array}{l}\text { Encargados y trabajadores en control de almacenes } \\
\text { y bodegas. }\end{array}$ & $\begin{array}{l}\text { Trabajadores de apoyo en actividades } \\
\text { agrícolas. }\end{array}$ \\
\hline Supervisores de operadores de maquinaria industrial. & $\begin{array}{l}\text { Barrenderos y trabajadores de limpieza } \\
\text { (excepto en hoteles y restaurantes). }\end{array}$ \\
\hline
\end{tabular}

Fuente: Elaboración propia con datos de la muestra censal de Inegi (2010).

Lo que ocurre en Puebla es que las principales ocupaciones femeninas son el trabajo doméstico, las operadoras de máquinas de costura, bordado y de corte para la confección de productos textiles y prendas de vestir, las secretarias, en la elaboración de pan, tortilla, repostería, y otros productos de cereales y harinas, las sastres y modistas, costureras y confeccionadores de prendas de vestir y las vendedoras ambulantes de artículos diversos (excluyendo los de venta de alimentos). En cambio, los hombres 
se ocupan en actividades relacionadas con la actividad agrícola, así como albañiles, mamposteros y afines, y conductores. Las ocupaciones que se clasificaron entre las 10 principales para ambos sexos son en el comercio y en el cultivo de maíz y/o frijol. A diferencia de Baja California, se trata de ocupaciones ligadas a actividades productivas menos salarizadas y propias de localidades rurales (Tabla 10).

Tabla 10: Puebla. 10 principales ocupaciones de la PEA según sexo, 2010

\begin{tabular}{|c|c|}
\hline Hombres & Mujeres \\
\hline Trabajadores en el cultivo de maíz y/o frijol. & Comerciantes en establecimientos. \\
\hline Albañiles, mamposteros y afines. & Trabajadores domésticos. \\
\hline $\begin{array}{l}\text { Otros trabajadores en actividades agrícolas no } \\
\text { clasificados anteriormente. }\end{array}$ & $\begin{array}{l}\text { Empleados de ventas, despachadores y } \\
\text { dependientes en comercios. }\end{array}$ \\
\hline Comerciantes en establecimientos. & $\begin{array}{l}\text { Operadores de máquina de costura, bordado } \\
\text { y de corte para la confección de productos } \\
\text { textiles y prendas de vestir. }\end{array}$ \\
\hline $\begin{array}{l}\text { Empleados de ventas, despachadores y } \\
\text { dependientes en comercios. }\end{array}$ & Secretarias. \\
\hline $\begin{array}{l}\text { Conductores de autobuses, camiones, camionetas, } \\
\text { taxis y automóviles de pasajeros. }\end{array}$ & $\begin{array}{l}\text { Otros especialistas no clasificados } \\
\text { anteriormente. }\end{array}$ \\
\hline Trabajadores de apoyo en la construcción. & $\begin{array}{l}\text { Trabajadores en la elaboración de pan, tortilla, } \\
\text { repostería, y otros productos de cereales y } \\
\text { harinas. }\end{array}$ \\
\hline $\begin{array}{l}\text { Conductores de camiones, camionetas y } \\
\text { automóviles de carga. }\end{array}$ & $\begin{array}{l}\text { Sastres y modistos, costureras y } \\
\text { confeccionadores de prendas de vestir. }\end{array}$ \\
\hline Trabajadores de apoyo en actividades agrícolas. & $\begin{array}{l}\text { Vendedores ambulantes de artículos diversos } \\
\text { (excluyendo los de venta de alimentos). }\end{array}$ \\
\hline Trabajadores en el cultivo de hortalizas y verduras. & Trabajadores en el cultivo de maíz y/o frijol. \\
\hline
\end{tabular}

Fuente: Elaboración propia con datos de la muestra censal de Inegi (2010).

En la Tabla 11, podemos constatar algunos de los hallazgos en relación con la mayor formalización del empleo en Baja California, lo cual se traduce en un mayor acceso a las instituciones de salud, tanto para hombres como para mujeres, pues los niveles de acceso para ambos sexos oscilan en alrededor de 50\%; situación muy diferente en Puebla, ya que en esta entidad, tanto hombres como mujeres, tienen escaso acceso a las instituciones de salud, y solamente alrededor de $20 \%$ de la población ocupada cuenta con esta protección social. 
Tabla 11: Distribución porcentual de la población ocupada según condiciones de acceso a instituciones de salud, primer trimestre de 2016

\begin{tabular}{|c|c|c|c|c|}
\hline & Hombre & $\%$ & Mujer & $\%$ \\
\hline \multicolumn{5}{|c|}{ Baja California } \\
\hline Total & 942502 & 100 & 589205 & 100 \\
\hline $\begin{array}{l}\text { Con acceso a } \\
\text { instituciones de salud }\end{array}$ & 480842 & 51 & 314748 & 53 \\
\hline $\begin{array}{l}\text { Sin acceso a } \\
\text { instituciones de salud }\end{array}$ & 411542 & 44 & 259812 & 44 \\
\hline No especificado & 50118 & 5 & 14645 & 2 \\
\hline \multicolumn{5}{|c|}{ Puebla } \\
\hline Total & 1603248 & 100 & 965796 & 100 \\
\hline $\begin{array}{l}\text { Con acceso a } \\
\text { instituciones de salud }\end{array}$ & 332392 & 21 & 189071 & 20 \\
\hline $\begin{array}{l}\text { Sin acceso a } \\
\text { instituciones de salud }\end{array}$ & 1269471 & 79 & 776004 & 80 \\
\hline No especificado & 1385 & 0 & 721 & 0 \\
\hline
\end{tabular}

Fuente: Elaborado con datos de la Enoe (Inegi, 2016a).

\section{Conclusiones}

La comparación de los mercados de trabajo regionales de México, nos ha sido útil para mostrar las grandes diferencias al interior del territorio nacional respecto a la heterogeneidad estructural y a los impactos diferenciados de la globalización económica, así como de la precarización laboral. Las regiones definidas aquí, como fronteriza y no fronteriza, resultan particularmente apropiadas para este análisis, ya que los modelos de desarrollo se han constituido a partir de distintos momentos del proyecto nacional y del desarrollo económico. Las regiones fronterizas son representativas de la etapa de apertura económica, neoliberalismo y globalización. En cambio, el modelo de desarrollo de la región no fronteriza, del centro del país, se configura en la etapa del modelo por sustitución de importaciones y, en un momento posterior, participa del proceso de relocalización industrial y apertura de la economía.

El contexto reciente para el análisis de los mercados de trabajo se caracteriza por los impactos de las crisis económicas de 2001 y 2008. Por otra parte, la ubicación geográfica de estas regiones, se traduce en procesos de poblamiento diferenciados. 
La región fronteriza se distingue por ser de alta migración, por lo que el mercado de trabajo se compone en una proporción muy importante de personas inmigrantes; es en este territorio donde la incorporación femenina al trabajo remunerado se encuentra en niveles más altos. Por su parte, la región no fronteriza, representada por Puebla, cuenta con una estructura productiva más polarizada y con mayor presencia de la población indígena y mayor peso de las actividades productivas de las localidades rurales.

En cuanto a la dinámica de los mercados de trabajo, podemos señalar que los empleos ofrecidos han sido insuficientes en ambas regiones, pero el impacto ha sido mayor en Baja California. Es aquí donde el deterioro de la calidad del empleo ha sido más acelerado en los últimos años, resultando en una caída de la atracción de la población migrante y un aumento de la tasa de condiciones críticas del empleo y del índice de la tendencia laboral de la pobreza. De tal modo que la precarización del trabajo se encuentra presente en ambos mercados laborales, pero con grados y expresiones distintas. En el caso de Puebla, se expresa por el escaso acceso de hombres y mujeres a las instituciones de salud, mientras que el problema principal en Baja California es la caída más intensa del poder adquisitivo del salario.

La estructura económica de ambos territorios tiene similitudes, en cuanto a la importancia relativa de los sectores primario, secundario y terciario. Esta distribución permite identificar la creciente terciarización existente en ambas economías. Sin embargo, en Puebla, hay una mayor actividad del sector agrícola, a diferencia de Baja California, donde el sector secundario es más importante. Lo anterior se encuentra correlacionado con la predominancia de las unidades económicas micro y grandes en Puebla, y de las pequeñas y medianas en Baja California.

En relación con la estructura ocupacional, vimos que por el peso del trabajo independiente (que incluye principalmente al trabajo por cuenta propia) este persiste, reproduciendo la heterogeneidad estructural, aunque con mayor extensión del trabajo asalariado en Baja California. Mientras que en Puebla, el trabajo independiente es ocupado por una tercera parte de la población ocupada, para los hombres, y una cuarta parte de las mujeres, quienes siguen teniendo un porcentaje importante de ocupaciones como familiares sin pago. En Puebla, el mercado de trabajo se caracteriza por la mayor presencia de trabajo atípico, pero ligado a la persistencia de economías de subsistencia.

Las diferencias en las ocupaciones principales según la condición migratoria y el sexo, nos permite dar cuenta de los procesos de segregación de la población inmigrante en el caso de Baja California, así como constatar la importancia del sector agrícola en Puebla y de las ocupaciones en la industria electrónica en Baja California, siendo las mujeres las que se ocupan principalmente en el ensamble de electrónicos. En cambio, las mujeres poblanas tienen entre sus ocupaciones principales las de ser operadoras de máquinas de costura, bordado y de corte para la confección de productos textiles y prendas de vestir. Estas ocupaciones femeninas predominantes en las dos regiones se vinculan a los empleos creados por la relocalización industrial global ocurrida en ambos territorios, pero que - en Puebla - se presenta en zonas rurales.

Las diferencias en los mercados de trabajo de estas regiones expresan los contrastes de los modelos de desarrollo regionales. La división norte-sur adquiere cierta relevancia y expresa temporalidades diferenciadas en el proceso de salarización y presencia de formas capitalistas de producción, así como problemáticas e impactos específicos de la globalización y de los ciclos de la actividad económica mundial. 
A partir de los resultados expuestos, también podemos constatar que la precarización laboral tiene dinámicas y alcances distintos de acuerdo con los contextos regionales. De tal manera que se puede distinguir entre un tipo de precariedad asociada con la persistencia de formas tradicionales de trabajo o economía de subsistencia de la época de la fábrica taylorista-fordista —en Puebla principalmente- junto con otra relacionada con la relocalización industrial, la flexibilidad del trabajo y la mayor importancia de la economía de los servicios, propios de la actual sociedad del conocimiento.

El trabajo atípico es parte de ambas economías, pero siguiendo distintas lógicas que tienen pesos diferenciados también en Puebla y Baja California. Un concepto de precariedad ampliado (y no restringido al trabajo asalariado) nos parece más apropiado para capturar la complejidad de las dinámicas de deterioro de la calidad del trabajo y de la brecha con el ideal marcado por el concepto de trabajo decente.

Regresando al punto de partida de este artículo, podemos decir que es necesario estudiar no solamente los mercados de trabajo regionales sino los mercados de trabajo locales, a nivel de las ciudades y municipios, con el fin de poder capturar las formas específicas en que se expresan los procesos globales y los impactos de las crisis de la primera década del siglo xxi. También podemos señalar que las regiones fronterizas tienen especificidades asocidas con su inserción en los proceso de globalización y que hoy en día muestran signos de estancamiento y deterioro de la calidad del empleo, que no se imaginaban en otros momentos del proceso de apertura económica.

\section{Agradecimientos}

Este artículo es producto de la investigación "Reconstruir el campo de las regiones no fronterizas en la relocalización industrial y la migración: Los casos de Marruecos y México", referencia cso2013-40646-P, que ha sido financiada por el Ministerio de Economía y Competitividad, a través de la Universidad de Granada, España.

\section{Referencias}

Acosta, F., Reyes, M. y Solís, M. (2015). Crisis económica, migración interna y cambios en la estructura ocupacional de Tijuana, México. Papeles de Población, 21(85), 9-46.

Aguirre, M. (2016). Series históricas del producto interno bruto de México 1896 hasta 2017. Recuperado del sitio de Internet de México máxico http://www.mexicomaxico. org/Voto/PIBMex.htm

Beck, U. (2006). La sociedad del riesgo: Hacia una nueva modernidad. Madrid, España: Paidós Ibérica.

Caire, G. (1982). Precarisation des emplois et regulation du marche du travail, Sociologie de Travail, 24(2), 135-158.

Consejo Nacional de Evaluación de la Política de Desarrollo Social (Coneval). (Febrero de 2016). Tendencias económicas y sociales de corto plazo. Resultados por entidad federativa. Recuperado de http://www.coneval.org.mx/Medicion/Documents/ ITLP/2015/4to_trim_2015/ITLP_ESTATAL_2016.pdf 
Cruz, R., Silva, Y. y Navarro, A. M. (2015). La migración interna en México: niveles y tendencias presentes y posibles. En Cruz, Rodolfo y Félix Acosta (coords.), Migración interna en México: Tendencias recientes en la movilidad interestatal (pp. 175200). México: El Colef.

De la Garza, E. (2011). Trabajo a-típico, ¿identidad o fragmentación?: Alternativas de análisis. En E. Pacheco, E. de la Garza y L. Reygadas (Coords.), Trabajos atípicos y precarización del empleo (pp. 48-108). México: El Colegio de México.

De la O, M. E. (2006). Geografía del trabajo femenino en México. Papeles de Población, 12(49), 91-126.

Di Filippo, A. y Jadue, S. (1976). La heterogeneidad estructural: Concepto y dimensiones. El Trimestre Económico, 43(169), 167-214.

Furtado, C. (1967). Teoría del desarrollo económico. México: Siglo xxi editores.

García, A. M. (1989). Patrones de desigualdad social en la sociedad moderna: Una revisión de la literatura sobre discriminación ocupacional y salarial por género. Desarrollo Económico, 29(114), 239-264.

Guillén, A. (2005). Integración, heterogeneidad estructural y empleo: El caso de México. Departamento de Economía de la Universidad Autónoma Metropolitana de Iztapalapa. Recuperado de la página de Internet de CADTM http://www.cadtm.org/ Integracion-heterogeneidad

Instituto Nacional de Estadística y Geografía (Inegi). (2000). XII Censo general de población y vivienda. México: Autor.

Instituto Nacional de Estadística y Geografía (Inegi). (2010). XIII Censo de población y vivienda. México: Autor.

Instituto Nacional de Estadística y Geografía (Inegi). (2011a). Perspectiva estadística Baja California. Diciembre de 2011. Recuperado de http://www.inegi.gob.mx/ est/contenidos/espanol/sistemas/perspectivas/perspectiva-bc.pdf

Instituto Nacional de Estadística y Geografía (Inegi). (2011b). Perspectiva estadística Puebla. México: Autor.

Instituto Nacional de Estadística y Geografía (Inegi). (2014a). Minimonografía. Baja California. Censos Económicos 2014. México: Autor.

Instituto Nacional de Estadística y Geografía (Inegi). (2014b). Minimonografía. Puebla. Censos Económicos 2014. México: Autor.

Instituto Nacional de Estadística y Geografía (Inegi). (2016a). Encuesta nacional de ocupaciones y empleo. Recuperado de http://www.inegi.org.mx/Sistemas/Olap/ Proyectos/bd/encuestas/hogares/enoe/2010_PE_ED15/po.asp?s=est\&proy=enoe_pe_ed15_po\&p=enoe_pe_ed15

Instituto Nacional de Estadística y Geografía (Inegi). (13 de mayo de 2016b). Resultados de la encuesta nacional de ocupación y empleo. Cifras durante el primer trimestre de 2016. Boletin de prensa núm. 209/16 http://www.inegi.org.mx/saladeprensa/boletines/2016/enoe_ie/enoe_ie2016_05.pdf

Instituto Nacional de Estadística y Geografía (Inegi). (s.f.). Sistema de cuentas nacionales. Producto interno bruto por entidad federativa. Recuperado de http:// www.inegi.org.mx/est/contenidos/Proyectos/SCN/C_Anuales/pib_ef/default.aspx 
Levar, L. (2011). Tasas de condiciones críticas de ocupación en el nivel más alto de la historia. Monitor Económico de Baja California. Recuperado de http://monitoreconomico.org/noticias/2016/jun/29/tasa-de-condiciones-criticas-de-ocupacion-de-bc-en-el-nivel-mas-alto-de-la-historia/

Mezzadra, S. (Enero de 2012). ¿Cuántas historias del trabajo? Hacia una teoría del capitalismo. Recuperado de http://eipcp.net/transversal/0112/mezzadra/es

Mallorquín, C. (2017). Los orígenes del neoestructuralismo latinoamericano. Estudios Regionales de Economía, Población y Desarrollo. Cuadernos de trabajo de la Universidad Autónoma de Ciudad Juárez, (39).

Mora, M. (2005). Ajuste y empleo: Notas sobre la precarización del empleo asalariado. Revista de Ciencias Sociales (Cr), II(108), 27-39.

Mora, M. (2010). Ajuste y empleo, la precarización del trabajo asalariado en la era de la globalización. México: El Colegio de México.

Mora, M. y De Oliveira, O. (2010). Las desigualdades laborales: Evolución, patrones y tendencias. En F. Cortés y O. de Oliveira (Coords.), V. Desigualdad social. Colección Los grandes problemas de México (pp. 101-140). México: El Colegio de México.

Organización Internacional del Trabajo (OIT). (2017). Trabajo decente. Recuperado de http://www.oit.org/global/topics/decent-work/lang-es/index.htm

Osorio, J. (2003). El neoestructuralismo y el subdesarrollo. Una visión crítica. Nueva Sociedad, (183), 134-150.

Pacheco, E. (2004). Ciudad de México, heterogénea y desigual: Un estudio sobre el mercado de Trabajo. México: El Colegio de México.

Prebisch, R. (1963). Hacia una dinámica del desarrollo latinoamericano: Con un apéndice sobre el falso dilema entre desarrollo económico y estabilidad monetaria. Nueva York, Estados Unidos de América: Naciones Unidas, Fondo de Cultura Económica.

Velasco, L., Coubés, M. L. y Zlolniski, C. (2015). De jornaleros a colonos: Residencia, trabajo e identidad en el Valle de San Quintín. México: El Colegio de la Frontera Norte.

Reygadas, L. (2011). Introducción: Trabajos atípicos, trabajos precarios: ¿Dos caras de la misma moneda? En E. Pacheco, E. de la Garza y L. Reygadas (Coords.), Trabajos atípicos y precarización del empleo (pp. 21-48). México: El Colegio de México.

Rojas, G. y C. Salas (2011). Precariedad laboral y la estructura del empleo en México. En E. Pacheco, E. de la Garza y L. Reygadas (Coords.), Trabajos atípicos y precarización del empleo (pp. 117-198). México: El Colegio de México.

Ruiz, P. y Ordaz, J. L. (2011). Evolución reciente del empleo y desempleo en México. Economía, 8(23), 91-105.

Marlene Solís

Mexicana. Doctorado en Ciencias Sociales con especialidad en Estudios Regionales por El Colegio de la Frontera Norte (El Colef). Profesora-investigadora del Departamento de Estudios Sociales y coordinadora del Doctorado en Estudios Culturales de El Colef, México. Líneas de investigación: género, trabajo y fronteras. Publicaciones recientes: Solís, M. y Ávalos, M. (2017). Construyendo ciudadanía laboral en la frontera norte de México, Trabajo y Sociedad, (29), 287-305; Solís, M (Edit.) (2016). Gender transitions along borders. The northern borderland of Mexico and Morocco. Londres: Routledge. 
Antonio Trinidad Requena

Español. Doctorado en Sociología por la Universidad de Granada. Catedrático de Universidad y Decano de la Facultad de Ciencias Políticas y Sociología de la Universidad de Granada (UGR). Docente e Investigador de la UGR, adscrito al Grupo de Investigación SEJ129: Problemas Sociales en Andalucía. Líneas de investigación: problemas sociales y migración. Publicaciones recientes: Requena, T., Soriano, A. y Barros, M. (2018). Localized Global Economies on the Northern Borderlands of Mexico and Morocco. La palgrave; Requena, T. y Barros, F. (2018). Las condiciones laborales en la industria exportadora del norte de Marruecos. Entre el marco legal y la realidad de los actores. International Labour Review, (157).

Rosa M. Soriano Miras

Española. Doctora en Sociología por la Universidad de Granada. Profesora Titular del Departamento de Sociología y Secretaria de la Facultad de Ciencias Políticas y Sociología en la Universidad de Granada (UGR). Líneas de investigación: problemas sociales y migración. Publicaciones recientes: Soriano-Miras, R.M. (2017). La posición geopolítica marroquí como frontera vertical de la Unión Europea. Cienciauat, 12(1), 52-69; Fajardo, R. y Soriano, R. M. (2017). The Mediterranean Sea as a border: difficulties surrounding the concept of migration. Revista Intermacional de Estudios Migratorios, 7(3), 198-218. 